\title{
Entrevista com Leonilde Servolo de Medeiros
}

Cristina Buarque de Hollanda

\section{Leonilde Medeiros}

Professora do Programa de Pós-graduação de Ciências Sociais em Desenvolvimento, Agricultu ${ }^{1}$ ra e Sociedade da Universidade Federal Rural do Rio de Janeiro (CPDA/UFRRJ) e pesquisadora do CNPq. Foi membro da Comissão Camponesa da Verdade e coordenadora de projeto Conflitos e repressão no campo no Estado do Rio de Janeiro financiado pela FAPERJ em colaboração com a Comissão da Verdade do Estado do Rio de Janeiro.

E-mail: leonildemedeiros@gmail.com

ORCID: https://orcid.org/0000-0001-5030-8044

\section{Cristina Buarque de Hollanda}

Professora do Instituto de Estudos Sociais e Políticos da Universidade do Estado do Rio de Janeiro.

E-mail: cristinabuarque@gmail.com

ORCID: https://orcid.org/0000-0002-1600-4044

\section{CRISTINA BUARQUE DE HOLLANDA:}

Leonilde, muito obrigada por me receber. Eu gostaria de começar te perguntando sobre a categoria de mortos e desaparecidos políticos da ditadura. Os movimentos de familiares [de mortos e desaparecidos] lutaram por muitos anos para construir essa ideia e também para inscrevê-la no vocabulário dos governos democráticos. Num passado mais ou menos recente, começa uma outra luta, pela inclusão de camponeses e indígenas nessa mesma etiqueta. E me parece haver uma disputa aí. Não é uma novidade necessariamente bem vista pelos militantes históricos da causa. Você poderia comentar sobre isso? Eu queria entender como você chegou na Comissão [Camponesa da Verdade, CCV], como ela funcionou e lidou - ou não - com essa categoria do desaparecimento político, porque vejo que, no relatório final, tem referências a desaparecimento forçado. Não se fala em desaparecimento político e não sei se isso chegou a ser uma questão para vocês.

\section{LEONILDE SERVOLO DE MEDEIROS:}

Essa é uma categoria usada pela Comissão Pastoral da Terra (CPT), que incorporamos.

CRISTINA BUARQUE DE HOLLANDA: Desaparecimento forçado?

\section{LEONILDE SERVOLO DE MEDEIROS:}

Desaparecimento, desaparecimento forçado. É interessante pensar em como surgiu a Comissão Camponesa. Houve uma coincidência: a Comissão [Nacional] da Verdade [CNV] foi criada em 2012. No final de 2011 foi o decreto que a instituiu [Lei 12.528, de 18 de novembro de 2011], mas ela começa efetivamente a operar em 2012 [16 de maio de 2012]. 
Em agosto de 2012, entre os dias 20 e 22, para ser precisa, houve um encontro, do qual não participei por conta de agenda, chamado Encontro Nacional Unitário de Trabalhadores e Trabalhadoras, Povos do Campo, das Águas e das Florestas.

\section{CRISTINA BUARQUE DE HOLLANDA:}

Isso está relatado logo no início do relatórioi.

\section{LEONILDE SERVOLO DE MEDEIROS:}

Ele foi um marco para a instituição da Comissão Camponesa da Verdade. Mas o Encontro não tinha, em princípio, nenhuma relação direta com o tema. Seu objetivo era reunir diversas organizações do campo e discutir uma pauta unitária de demandas e lutas. Porém, na Declaração Final, havia um item no qual, aproveitando a instalação da Comissão da Verdade [CNV], propunha-se que fossem esclarecidos os crimes da ditadura contra camponeses. Esse era um ponto entre diversas outras demandas dos mais diferentes tipos. A partir dele, um grupo de pesquisadores - e uma das principais figuras articuladoras foi o professor Sérgio Sauer da UnB [Universidade de Brasília] - se sentiu instigado a trabalhar com o tema. Ele já tinha relações anteriores com diferentes movimentos e com outros presentes no Encontro. Começou-se a pensar na possibilidade de se constituir um grupo basicamente constituído por acadêmicos, mas com participação e respaldo muito forte de alguns movimentos sociais, para começar uma investigação sobre o que foi a ditadura no campo, as formas de repressão utilizadas etc.

\section{CRISTINA BUARQUE DE HOLLANDA:}

Você tem alguma pista de quem instigou? Porque você disse que o Sauer "se sentiu instigado". Tem algum ator institucional aí?

\section{LEONILDE SERVOLO DE MEDEIROS:}

A Contag [Confederação Nacional dos Trabalhadores na Agricultura] teve um papel importante nessa articulação. À época, ela tinha uma assessora, a Nicinha [Clea Nice Porto], que é uma pessoa muito ativa e que foi uma das primeiras a começar: ela, o Sérgio Sauer, algumas pessoas do MST [Movimento dos Trabalhadores Rurais Sem Terra], o Antonio Canuto da Comissão Pastoral da Terra (CPT) e o próprio Gilnei Viana. É difícil falar do Gilnei, porque ele participa não exatamente como um representante do Estado, mas como Gilnei. Ele era Estado, na medida em que tinha um cargo de gestão. Não dá para separar essas coisas, mas ele não estava no grupo como um representante do Estado. Nessa época, o Gilnei estava finalizando o livro sobre os mortos e desaparecidos no campoii. Então, começou uma articulação de pesquisadores. Fui chamada, perguntaram se eu teria interesse em participar e falei "claro!". Alguns orientandos meus também se envolveram e começamos a trabalhariii. A questão era ver como encaminhávamos as atividades. Até fazer essa articulação inicial e reunir as pessoas levou um certo tempo e começamos em meados de 2013.

\section{CRISTINA BUARQUE DE HOLLANDA:}

Uma coisa que me chamou a atenção foi a quantidade de comissionários. Algo em torno de 60 pessoas, talvez.

\section{LEONILDE SERVOLO DE MEDEIROS:}

Participaram muitas pessoas, mas com graus diferentes de envolvimento. O grupo articulador fez contato com a CNV [Comissão Nacional da Verdade], com a Maria Rita Kehl, 
responsável pelo GT [Grupo de Trabalho] Camponeses e Indígenas, e foi bem recebido. Daí deriva esse caráter semioficial que o grupo tinha porque, por exemplo, nós nos reuníamos em Brasília e as passagens eram pagas pela CNV. Mas não tínhamos diárias, então ficávamos hospedados na Contag - que tem, no Núcleo Bandeirantes, próximo a Brasília, um alojamento grande para os cursos de formação que ela faz para o seu público - e fazíamos as refeições lá. Quando possível, um carro da Contag ia nos buscar no aeroporto ou nos levar para lá, no final das reuniões.

\section{CRISTINA BUARQUE DE HOLLANDA:}

Os encontros eram sempre em Brasília?

\section{LEONILDE SERVOLO DE MEDEIROS:}

Sempre em Brasília e sempre na Contag, onde há uma excelente infraestrutura para reuniões desse tipo, justamente porque tem um refeitório grande, dormitórios etc. e tudo em um espaço relativamente pequeno, o que promove uma convivência intensa. Ficávamos lá o tempo inteiro e fazíamos a reunião em um dia ou em um dia e meio. Se quiséssemos ir na véspera para já dormir lá e começar a reunião às $9 \mathrm{~h}$, nenhum problema.

Quais as pessoas que participaram ativamente dessas reuniões? Nós fizemos, ao que me lembro, três ou quatro reuniões ao longo do período. Pelo menos de três lembro de que participei. Éramos Sério Sauer, a Nicinha da Contag, a Juliana Moretti, que era ligada ao MST, e mais uma série de acadêmicos, de vários estados, cujos nomes constam do relatório que entregamos à CNViv. Tinha a Clélia Botelho da Costa, de Goiás; o Cliff Wellch, de São Paulo; o Girolamo Treccani, que teve um papel muito importante porque é advogado e professor de Direito na [Universidade] Federal do Pará e tem vínculos muito fortes com a CPT, com as lutas sociais; Moacir Palmeira, do Museu Nacional da UFRJ, Marta Cioccariv, Pablo Porfírio, da Federal de Pernambuco, Alessandra Gasparotto, da Federal de Pelotas. As reuniões envolviam em torno de 30 pessoas, às vezes um pouco mais, outras um pouco menos, então não era tão pequena. Alguns dos participantes acabaram não escrevendo textos.

\section{CRISTINA BUARQUE DE HOLLANDA:}

Isso chama a atenção, porque as outras comissões, em geral, têm sete membros.

\section{LEONILDE SERVOLO DE MEDEIROS:}

Não éramos membros, entende? Éramos pessoas que aderiram à ideia e colaboravam como podiam...

\section{CRISTINA BUARQUE DE HOLLANDA:}

Não havia esse status do comissionado.

\section{LEONILDE SERVOLO DE MEDEIROS:}

Não, não tínhamos status algum! Nós nos autodenominamos Comissão Camponesa e pronto. Isso surgiu de conversas informais: "Quem é que vai na reunião da Comissão Camponesa?" e ficou por aí, não tínhamos nenhum status. Nós dialogamos, em cada uma dessas reuniões, com Maria Rita Kehl, que era comissionada, mas ela não participava das reuniões inteiras. Ia num período, nos ouvia, falava sobre o que estava interessada em pesquisar. 
Em uma das reuniões, veio também a Heloisa Starling [professora UFMG] e mais alguns pesquisadores do seu grupo, que queriam saber o que estávamos fazendo. Esse diálogo foi, em alguns momentos, um pouco tenso, porque havia uma linha da comissão da CNV que tinha o olhar muito atento para os grupos de esquerda organizada e suas diversas articulações. Por exemplo, a Maria Rita estava absolutamente fascinada pela Guerrilha do Araguaia e nós insistíamos muito: "Maria Rita, a Guerrilha do Araguaia foi fundamental, mas não resume e nem exatamente representa o que foi a luta camponesa no período. Ela é uma faceta". Enfim, os interesses acabavam sendo mesmo distintos. Esse grupo que se reunia era, basicamente, de pesquisadores, como já disse; três ou quatro pessoas eram de movimentos. O que nos juntava? Um acúmulo de pesquisas sobre conflitos no campo. $\mathrm{E}$, se você lê o relatório, percebe que ele agrega resumos maiores ou menores de pesquisas que identificamos. Frente à impossibilidade de se fazer pesquisa original (não tínhamos recursos para isso), o que podíamos fazer era tentar resgatar um pouco do que existia já produzido, seja em forma de artigos, teses, dissertações, livros, capítulos...

\section{CRISTINA BUARQUE DE HOLLANDA:}

Com esse espírito de compilar um saber já existente, mas disperso, o relatório concentraria isso.

\section{LEONILDE SERVOLO DE MEDEIROS:}

Exatamente, sem grandes pretensões. A nossa ideia era mostrar que tinha havido uma repressão intensa no campo e que era importante trazer os fatos à luz. Tínhamos clareza que não íamos investigar esse processo a partir de fontes primárias.

\section{CRISTINA BUARQUE DE HOLLANDA:}

Não tinham pernas para isso.

\section{LEONILDE SERVOLO DE MEDEIROS:}

Não tínhamos perna, de jeito nenhum!

\section{CRISTINA BUARQUE DE HOLLANDA:}

E não chegou a ter oitivas, sessões de testemunhos?

\section{LEONILDE SERVOLO DE MEDEIROS:}

Não, nada, nada. Foi trabalho essencialmente bibliográfico. Não chegamos a fazer quantificações e nem fazíamos um trabalho muito apurado de categorias, entende? Termos como "desaparecimento forçado" apareceram para tentar dar conta de situações que estávamos encontrando, mas que não possuíam quantificação rigorosa. Tentamos construir alguns quadros, mas nos escapava das mãos a possibilidade de fazer qualquer coisa um pouco mais aprofundada e sistemática.

\section{CRISTINA BUARQUE DE HOLLANDA:}

Você mencionou que eram muitos acadêmicos e que tinham três ou quatro representantes de movimento. Como era essa interlocução? Isso chama a atenção em relação a outras comissões, em que os "nativos", digamos, estavam presentes, eles próprios articulavam a fala sobre si. Nesse caso, em que a maioria de membros da comissão era de mediadores, como vocês interagiam com as figuras que eram dos próprios movimentos? 


\section{LEONILDE SERVOLO DE MEDEIROS:}

Eles estavam presentes nas reuniões, contribuíam, mas foi um trabalho fundamentalmente bibliográfico, com uma ou outra fonte jornalística. Cada um pegou algumas coisas que tinha consigo para uma pesquisa que estava fazendo, mas que ainda não estava acabada, teses e dissertações, artigos, algumas matérias jornalísticas, e fazia uma sistematização, mas era basicamente bibliográfico. Os representantes dos movimentos acompanhavam, lembravam de um evento ou outro que era importante a gente recuperar, algum caso... Eles não puxavam a discussão, era um diálogo conosco. Eles iam às reuniões, ouviam o que estávamos falando e falavam "Ah, em tal região teve uma coisa parecida assim".

\section{CRISTINA BUARQUE DE HOLLANDA:}

Contribuíam com a memória dos eventos?

\section{LEONILDE SERVOLO DE MEDEIROS:}

Contribuíam com a memória de alguns eventos e foi, basicamente, isso. Há que pensar que os movimentos também conhecem pouco dessa história vivenciada nos anos que se sucederam ao golpe. Conhecem mais o que ocorreu antes, as grandes mobilizações e lutas que antecederam o golpe e a retomada das mobilizações nos anos 1980.

Nós começamos a trabalhar com a ideia de fazer uma ficha para cada conflito, que o localizasse, registrasse o número de envolvidos, as ocorrências principais... Até um determinado momento, conseguimos caminhar com essas fichas. Tentávamos preenchê-las a partir do material de que dispúnhamos, mas, de repente, não tínhamos mais pernas nem para fazer isso, tal o volume de informações, embora bastante desiguais.

\section{CRISTINA BUARQUE DE HOLLANDA:}

Isso exigiria, talvez, um trabalho de investigação para complementar o que vocês não tinham já apurado...

\section{LEONILDE SERVOLO DE MEDEIROS:}

Exatamente, exatamente! Exigia um trabalho de pesquisa que envolveria deslocamentos, viagens. Não fazíamos isso nas capitais, que é onde estava a maioria dos pesquisadores que se reunia no grupo. Era necessário ir a campo, localizar pessoas, criar aproximação, ouvir, buscar documentos sindicais, da Igreja...

\section{CRISTINA BUARQUE DE HOLLANDA:}

Fazer trabalho de campo, né?

\section{LEONILDE SERVOLO DE MEDEIROS:}

Um trabalho de campo intenso! Logo percebemos que não íamos ter condições para tudo isso.

\section{CRISTINA BUARQUE DE HOLLANDA:}

Alguns de vocês se dedicavam exclusivamente a isso ou todos tinham a Comissão como mais uma atividade da agenda?

\section{LEONILDE SERVOLO DE MEDEIROS:}

Não... Era uma tarefa a mais na nossa vida, não tinha ninguém exclusivamente dedicado. Todos nós estávamos dando nossas aulas, orientando, fazendo nossas pesquisas... Como 
disse antes, havia inclusive alguns estudantes de pós-graduação que deram uma contribuição importante. A própria ideia de fazer fichas: começamos com elas, tentamos fazer, discutimos muito o modelo, que tipo de informações seria interessante - porque daí teríamos algo que poderia ser quantificado, comparado -, mas não conseguimos ir muito longe porque exigiria um outro tipo de trabalho que não tínhamos condição de fazer. Optamos por fazer o que era possível, porque todas as pessoas mantinham suas atividades profissionais e a elas acrescentavam-se os trabalhos para a CCV.

\section{CRISTINA BUARQUE DE HOLLANDA:}

E esse objeto de campo de vocês tem dificuldades importantes que eu lembro de você relatar naquele seminário no IESP [Instituto de Estudos Sociais e Políticos da Universidade do Estado do Rio de Janeiro] ${ }^{\text {vi }}$. Uma dificuldade adicional dos mortos e desaparecidos do campo em relação aos mortos e desaparecidos do asfalto, digamos, era a própria identidade dessas pessoas.

\section{LEONILDE SERVOLO DE MEDEIROS:}

É.

\section{CRISTINA BUARQUE DE HOLLANDA:}

Talvez fossem pessoas que sequer tivessem registro formal de nascimento, não?

\section{LEONILDE SERVOLO DE MEDEIROS:}

Talvez. O Antônio Canuto, da CPT, sempre chamava a atenção para esse ponto. Toda a trajetória de trabalho do Canuto na CPT foi no Mato Grosso, com Dom Pedro Casaldáliga. Ele lidou muito mais com essa situação de pessoas que talvez nem tivessem registro de nascimento. Na verdade, não se tinha nem como saber se tinham registro ou não, porque, para ir atrás, era preciso ter um nome e o Canuto insistia bastante no fato de que, em muitos casos, tinha-se apenas um apelido. Também nos defrontamos com isso na pesquisa que fizemos sobre o Rio de Janeiro.

\section{CRISTINA BUARQUE DE HOLLANDA:}

Porque era praxe que as pessoas não se chamassem pelo nome.

\section{LEONILDE SERVOLO DE MEDEIROS:}

É, as pessoas se conhecem pelos apelidos. Dificilmente uma pessoa conhece um vizinho, com o qual ele convive há 10, 20 anos, pelo nome e sobrenome. Especialmente nas áreas rurais, não é isso que ocorre. As pessoas se conhecem pelo "o Zé da Ana", coisa desse tipo. Essa é uma dificuldade adicional que nós enfrentávamos e que é um desafio para esse tipo de pesquisa. Quem passou por IPMs [Inquéritos Policiais Militares] ou mesmo quem foi preso e teve ficha policial e, portanto, está nos arquivos do DOPS [Departamento de Ordem Política e Social], são as pessoas que tiveram protagonismo maior. Mas isso, para o campo, foi minoria, porque muitos militantes de base fugiram após o golpe. No campo, há maior facilidade para se esconder, eles estão num terreno que conhecem bem... O caso do Bráulio Rodrigues da Silva é exemplar - foi uma liderança que morreu há pouco, em setembro de 2019. Ele me falava que ficou dois anos na Baixada Fluminense, em casas de amigos, conhecidos, indo de um lugar para outro, e não foi preso de imediato. Só o prenderam três ou quatro anos depois do golpe. vii Nessa ocasião, ele foi "fichado" e há o habeas data dele com algumas de suas atividades. Mas, para a maioria, não havia nem isso, era um pouco "fica preso, fica solto...". Há uma acusação, mas não há muito como desdobrar, entende? E 
essa é uma situação própria de lideranças. José Pureza, que foi uma outra liderança importante do estado do Rio de Janeiro, foi preso bem depois do golpe e não de imediato. Foi preso no Nordeste... Enfim, as pessoas encontravam seus caminhos para "sumir do mapa".

\section{CRISTINA BUARQUE DE HOLLANDA:}

Rotas de fuga.

\section{LEONILDE SERVOLO DE MEDEIROS:}

E os que foram presos foram lideranças mais de ponta; as lideranças intermediárias, em algumas situações sim, em outras não. Por exemplo, na pesquisa que fizemos sobre o Rio de Janeiro, ficamos surpresos com o grande número de presos em um único município.

\section{CRISTINA BUARQUE DE HOLLANDA:}

Qual município?

\section{LEONILDE SERVOLO DE MEDEIROS:}

Cachoeiras de Macacu, um município que teve duas importantes ocupações de terra antes do golpe, que tinha um prefeito, Ubirajara Muniz, que era do PTB [Partido Trabalhista Brasileiro] e que apoiava muito as lutas... Tornou-se um caldeirão de conflitos. Havia lá um projeto de colonização de 1951, época do governo de Getúlio Vargas, que atraiu muita gente. Enfim, uma série de situações muito particulares. Mas o fato é que, em geral, na Comissão Camponesa, nós tínhamos uma certa dificuldade para descobrir a localização das pessoas, aprofundar suas histórias etc... Para isso seria necessário um investimento enorme que não tínhamos condição de levar adiante. Portanto, o que procuramos, o que tínhamos perna para fazer era mostrar a amplitude dos conflitos e um pouco da sua natureza, em torno do que esses camponeses estavam lutando e como a repressão se abateu sobre eles. Aqueles resumos todos que constam do Relatório da CCV têm isso em comum.

\section{CRISTINA BUARQUE DE HOLLANDA:}

Você diria que entre os atingidos pela ditadura no campo existe uma percepção de distinção clara entre democracia e ditadura? Eu te faço essa pergunta pelo seguinte: quando escutei uma liderança Krenak em seminário no CBAE [Colégio Brasileiro de Altos Estudos] da UFR] [Universidade Federal do Rio de Janeiro], ele falava: "a nossa ditadura militar começou em 1500". Para ele, a experiência do tempo é a de uma longa continuidade da violência, sem marcadores de distinção histórica.

\section{LEONILDE SERVOLO DE MEDEIROS:}

De alguma forma é um marco relativo, pois a violência antecede de muito o golpe e continua após a redemocratização, até os dias de hoje.

\section{CRISTINA BUARQUE DE HOLLANDA:}

Em todas as Comissões da Verdade que eu estudei no Brasil, o recorte formal de investigação é o período de 1946 a 1985. Seus documentos de criação em geral espelham a lei da CNV, que tem a mesma referência temporal. Foi parte dos acordos com militares.

Mas, na prática, as comissões praticamente ignoraram o período que antecede o golpe. No caso da Comissão Camponesa, o relatório deixa muito claro que o período que antecede 0 golpe é, evidentemente, muito relevante. Eu fiquei me perguntando se existe no campo uma ideia clara de ditadura como coisa distinta da democracia, se isso é uma coisa 
relevante, ou se talvez essa seja uma etiqueta que a própria comissão, por conta das circunstâncias da sua criação, acaba operando, mobilizando para...

\section{LEONILDE SERVOLO DE MEDEIROS:}

É claro que o golpe é um divisor de águas, mas isso não quer dizer que as situações de repressão só começaram com ele. No caso do campo, você tem um crescimento das mobilizações inicialmente muito molecular. A partir de 1946, 47, há um aumento de criação de associações, irmandades, nomes vários dados a organizações locais, com base em áreas de conflitos. Concordo com o Krenak: vem desde 1500.

No entanto, qual é a grande diferença do final dos anos 1940, quando os movimentos camponeses começam a ter maior visibilidade, diferentemente do que ocorreu com os indígenas, que só tiveram essa visibilidade nos anos 1980? Organização, articulação nacional com bandeiras comuns. Temos um primeiro congresso nacional de lavradores em 1953, um segundo em 1954, quando foi criada uma associação, que se pretendia nacional, de lavradores e trabalhadores agrícolas [União dos Lavradores e Trabalhadores Agrícolas do Brasil], e já com representantes de vários estados. Essa organização foi crescendo, foram se criando federações e associações de lavradores em diferentes unidades da federação ao longo dos anos 50, e culminou, em 61, com o Congresso Nacional Camponês de Belo Horizonte, um divisor de águas, porque juntou cerca de 1600 representantes de camponeses de todos os pontos do Brasil, com articulações muito evidentes, mas também tensões com o Estado, por exemplo. O Congresso se realizou em Belo Horizonte e quem cedeu o espaço foi o então Governador Magalhães Pinto. O presidente João Goulart esteve no encontro... Era um momento político difícil, o congresso foi, inclusive, adiado por conta da renúncia do Jânio Quadros em agosto de 1961. Enfim, o congresso foi realizado em um momento tenso e, mesmo assim, teve um número significativo de representantes. É difícil reconstituir os momentos e principalmente os bastidores desse encontro somente por meio da imprensa comunista, dos relatos. Mas chama a atenção um fato: acabado o congresso, começaram a ocorrer, no início de 1962, ocupações de terras em diferentes pontos do país. Então, acho que essas coincidências não podem ser desconsideradas...

\section{CRISTINA BUARQUE DE HOLLANDA:}

Claro.

\section{LEONILDE SERVOLO DE MEDEIROS:}

Quando começaram as ocupações, intensificaram-se as ações repressivas de governos estaduais.

\section{CRISTINA BUARQUE DE HOLLANDA:}

Estaduais com as polícias militares.

\section{LEONILDE SERVOLO DE MEDEIROS:}

Isso, embora em alguns lugares sem esse nome. Também foi um período de eleição de novos governadores. Por exemplo: Leonel Brizola perdeu a eleição, no Rio Grande do Sul, para Ildo Meneghetti; em São Paulo foi eleito Adhemar de Barros, em substituição a Carvalho Pinto, que havia criado um "Projeto de revisão agrária", tentando responder às lutas por terra no estado. No Rio de Janeiro foi escolhido Badger da Silveira, que era PTB, mas não era o mesmo PTB do irmão dele, Roberto Silveira, que tinha dado um certo apoio às lutas no campo. Enfim, você tem aí conjunturas estaduais que, em alguns casos, abriram 
portas e em outros as fecharam. No caso do Nordeste, foi eleito o Miguel Arraes, que permitiu uma intensificação da mobilização camponesa.

Voltando ao tema da ditadura e da democracia, se você observar o livro de Ana Carneiro e Marta Cioccariviii, a periodização é outra, inicia em 1962. Acho uma periodização mais coerente, pois é um momento em que há uma mudança de conjuntura. Há claramente a emergência de um movimento camponês, com diferentes correntes que disputam entre si, mas que efetivamente está colocando a questão da reforma agrária e dos diretos trabalhistas na ordem do dia. Em alguns lugares, a repressão foi muito grande, mas, conforme a situação, a repressão já vinha muito de antes. Por exemplo, em São Paulo, com o movimento que ficou conhecido como "arranca capim". No Rio, houve várias situações de prisão, mas também de regularização de terras de posseiros, com desapropriação dos que alegavam ser os donos delas.

\section{CRISTINA BUARQUE DE HOLLANDA:}

Muito heterogêneo, depende das circunstâncias locais.

\section{LEONILDE SERVOLO DE MEDEIROS:}

Muito heterogêneo. Depende das circunstâncias locais, de quem está envolvido localmente. Há exemplos para tudo, mas a repressão, seguramente, não começou com o golpe. Mas há diferença, porque depois do golpe a repressão se intensificou muito! Nos locais de conflito, houve uma repressão brutal: militares, policiais entraram com brutalidade nas casas dos lavradores para procurar armas. "Cadê os comunistas?", um vocabulário que, muitas vezes, os camponeses não entendiam bem.

\section{CRISTINA BUARQUE DE HOLLANDA:}

Pois é, eu ia chegar aí. Queria te perguntar sobre isso, porque possivelmente não vocalizavam a luta pela terra como luta de classes. Quer dizer, não partiam necessariamente do léxico e do repertório comunista.

\section{LEONILDE SERVOLO DE MEDEIROS:}

Não, não. A bandeira da reforma agrária era defendida, nessa época, por várias forças ...

\section{CRISTINA BUARQUE DE HOLLANDA:}

Não falavam em reforma agrária, simplesmente queriam a terra...

\section{LEONILDE SERVOLO DE MEDEIROS:}

Só queriam ficar na terra onde eles estavam com suas famílias, ou, em outros casos, queriam salário, melhorias das condições de trabalho. Mas por que que a palavra "comunista" entrava tão fortemente? Porque o grande articulador dessa unificação camponesa foi o Partido Comunista, em que pese o fato de que, depois, outras forças políticas (Ligas, Igreja) tenham entrado na disputa pela organização dos camponeses.

Desde do pós-guerra eles difundem a bandeira da Aliança Operária Camponesa. Nesse momento, eles tinham penetração em alguns setores operários, mas não tinham ideia do que era o camponês e deslocaram alguns quadros para o campo. Eles se deslocaram para locais onde sabiam que havia conflitos ou sinais de tensões. Então, as recorrentes tensões do campo são potencializadas por esse trabalho articulador. 


\section{CRISTINA BUARQUE DE HOLLANDA:}

Então foi um trabalho muito eficiente.

\section{LEONILDE SERVOLO DE MEDEIROS:}

Foi, foi. Eles conseguiram fazer um jornal voltado estritamente para o campo, tentando falar uma linguagem mais acessível, um jornal cheio de ilustrações etc. que teve alguma penetração: o Terra Livre, que começou a ser editado em 1949. Era o chamado Partidão, porque, nesse momento, não tinha ainda o PCdoB. A cisão é em 1962. Nesse momento, é um partido que tem diversas disputas internas, diferenças etc. O PCdoB não nasce do nada, não foi conjuntural. De toda forma, há um trabalho que teve alguma eficácia no sentido de articular lutas locais em uma bandeira mais geral e dar conteúdo para o que era a bandeira da Aliança Operária Camponesa, a reforma agrária.

\section{CRISTINA BUARQUE DE HOLLANDA:}

Eles mapeavam os centros de tensão local, entendiam que ali já havia pessoas mobilizadas e buscavam estimular um certo enquadramento para ler a situação.

\section{LEONILDE SERVOLO DE MEDEIROS:}

Mandavam seus quadros... quando tinham, porque também não era essa potência toda, capaz de cobrir o país... Por vezes, esses próprios quadros, nas suas andanças, por relações pessoais etc. acabavam chegando a áreas de conflitos. A impressão que eu tenho, tomando o caso do Rio de Janeiro, que é o que conheço melhor, é que esses quadros não necessariamente eram profundamente articulados com o PCB, entende? Tinham uma certa autonomia, até também porque o partido não conseguia um controle tão grande sobre as ações locais. Isso me chamou a atenção. Por exemplo, a partir de 1958, o partido mudou sua linha política, para tentar ampliar seu arco de alianças com setores progressistas etc. e estavam em um movimento de tentar pressionar por uma reforma agrária a partir de mudanças legais. Nesse momento, início dos anos 60, começaram a ocorrer ocupações de terra. Não era exatamente o que estava no programa do partido, mas no Rio de Janeiro, o PCB acabou chancelando-as. Quando houve a ocupação do Imbé, em Campos, o fato foi manchete de primeira página do jornal Terra Livre. Na própria leitura dos jornais, percebemse essas tensões internas. Quando se chega nos camponeses, nos lugares de conflito, eles não falam da "revolução brasileira", das "transformações sociais", do "socialismo", "comunismo". A questão deles é...

\section{CRISTINA BUARQUE DE HOLLANDA:}

Uma ação de consequência mais imediata.

\section{LEONILDE SERVOLO DE MEDEIROS:}

Mais imediata. É permanecer na terra onde estavam, onde investiram, melhoria das condições de trabalho, "terra para quem nela trabalha" que, não por acaso, era o subtítulo do Terra Livre.

\section{CRISTINA BUARQUE DE HOLLANDA:}

Em analogia com o que você me conta, imagino que também agora, em um recorte mais contemporâneo, a aproximação da questão camponesa com todo esse vocabulário da justiça de transição seja obra, talvez, da própria Comissão Camponesa ou da CNV... O direito à memória, o direito à verdade... 


\section{LEONILDE SERVOLO DE MEDEIROS:}

No que consigo perceber: isso não aparece. Mas, a partir da minha experiência de pesquisa no estado do Rio de Janeiro, quando chegávamos nos lugares e falávamos que estava fazendo uma pesquisa sobre os conflitos, nós não chegávamos com o vocabulário de Comissão da Verdade. Se achávamos que eles conheciam, falávamos. Caso contrário, dizíamos que o nosso desejo era conhecer as lutas do passado, como tinham sido, se houve muita violência, se o Estado também tinha ajudado, que era um outro lado que queríamos pegar. Naqueles anos da pesquisa (2014/2015), o tema circulou muito nos jornais, na televisão... Então, eles tinham alguma noção: "Ah, eu ouvi falar na televisão..."

\section{CRISTINA BUARQUE DE HOLLANDA:}

Tinham ouvido falar pela televisão, e não por gerações anteriores?

\section{LEONILDE SERVOLO DE MEDEIROS:}

A televisão começava a falar do que tinha acontecido na ditadura, que as comissões queriam saber etc., mas eles não se sentiam muito atingidos por isso. De alguma maneira, quando fazíamos as entrevistas, provocávamos a construção de relações que eles não necessariamente faziam espontaneamente. Mas acho que a questão deles era a luta local, eram as demandas mais imediatas e quando apareciam essas "pessoas de fora", que não eram de fora no sentido de que iam e vinham, eram pessoas que se estabeleciam nos locais e que, nessa medida, viravam "de dentro" e se envolviam completamente nas lutas. Algumas pessoas lembravam de algumas lideranças e falavam delas com carinho: "ah, eu lembro que ele me dava bala!" Era uma relação sobre a qual você não pode pensar estritamente do ponto de vista da política, elas envolvem diversos planos de relações, inclusive as afetivas.

Mas, voltando ao ponto em discussão, a repressão começou antes. Em 1964, a repressão se intensificou muito e aí aparecem esses fantasmas, um vocabulário que não juntava com o deles: "Cadê os comunistas? Cadê as armas? Cadê... o líder?". Não se coadunava também com as relações vivenciadas.

\section{CRISTINA BUARQUE DE HOLLANDA:}

Entendi. Tinha uma dificuldade até de comunicação.

\section{LEONILDE SERVOLO DE MEDEIROS:}

É! O que é visível é que eles chegaram com muita violência e a linguagem da violência é que fazia a comunicação, ou a não comunicação.

\section{CRISTINA BUARQUE DE HOLLANDA:}

Claro.

\section{LEONILDE SERVOLO DE MEDEIROS:}

E a violência mostra o desencontro do que os agentes da Polícia do Exército pensavam e o que as pessoas comuns pensavam. Por exemplo, eu tive uma narrativa de um militante que, quando veio o golpe, ele se escondeu. As filhas já não estavam com ele, porque ele tinha ficado viúvo e deixou as meninas com os pais da esposa. Ficou com os meninos. Ele saia de casa durante o dia, ia para lugares mais difíceis e voltava à noite, para ver como estavam os meninos: dormia em casa e saía antes de amanhecer. Obviamente a polícia desconfiou, deve ter percebido alguns movimentos. Pegaram um dos meninos e colocaram o revólver na 
sua boca para que ele dissesse onde estava o pai. Uma criança de nove anos... O nível de brutalidade era muito grande...

Voltando à Comissão Camponesa, só se consegue essas informações conversando muito com as pessoas. Elas não estão registradas em lugar nenhum, nem em IPMs, nem em arquivos públicos, nem nos documentos do DOPS. É um padrão de violência cotidiana que só se consegue conhecer por meio dos depoimentos. Quando os militares ou a polícia percebiam que as pessoas realmente não atinavam o que estava acontecendo, acabavam indo embora, porque buscavam lideranças, os que estavam à frente.

\section{CRISTINA BUARQUE DE HOLLANDA:}

E a articulação, também, que havia com as forças de repressão privadas que não eram...

\section{LEONILDE SERVOLO DE MEDEIROS:}

As forças de repressão privadas, essas que foram, tradicionalmente, violentas na história do Brasil...

\section{CRISTINA BUARQUE DE HOLLANDA:}

Entendi. Você acrescenta ao que já era uma violência rotineira, cotidiana, a presença dos agentes de Estado.

\section{LEONILDE SERVOLO DE MEDEIROS:}

Sim, a violência cotidiana, costumeira dos capangas, jagunços, coisas desse tipo, mais a presença dos agentes de Estado.

\section{CRISTINA BUARQUE DE HOLLANDA:}

Porque um dos grandes pleitos da Comissão é que essa violência não praticada, mas consentida pelo Estado, também seja reconhecida como violência do Estado.

\section{LEONILDE SERVOLO DE MEDEIROS:}

Sim, e aí você volta a 1500, né?

\section{CRISTINA BUARQUE DE HOLLANDA:}

Pois é!

\section{LEONILDE SERVOLO DE MEDEIROS:}

Quando você olha a história dos movimentos camponeses no Brasil, você encontra a presença forte do Estado em alguns casos emblemáticos: Canudos, Contestado... O Exército veio com toda a força. Regra geral, era o poder privado que resolvia - resolvia, obviamente, com aspas... É um mundo onde o Estado, efetivamente, estava presente pela omissão. Os grandes proprietários eram responsáveis tanto pela punição de possíveis tentativas de organização, como também pelo mínimo de assistência que as pessoas tinham. Um caso em que o Estado esteve presente foi nas greves dos colonos do café, no início do século XX, em São Paulo. Foi quando o governo estadual criou uma instituição, o Patronato Agrícola, e instituiu as cadernetas agrícolas, que é uma precursora da carteira de trabalho, quando nem os trabalhadores urbanos ainda a tinham. Nela se registravam as tarefas do colono, quanto ele colhia etc., para poder fazer o acerto de contas no final da colheita. Ou seja: em alguns momentos, o Estado entrava, mas não era essa a regra. Nesse sentido, creio que o Partido Comunista teve importância muito grande, no sentido de tornar essas questões problemas públicos. Trazer isso à tona, articular a resistência a partir de algumas demandas, trazer 
para o debate e construir essas situações como um problema público. Esse foi o trabalho dos militantes nos anos 1950 e 60.

\section{CRISTINA BUARQUE DE HOLLANDA:}

E depois da volta para a democracia? Imagino que assim como a marcação de ingresso na ditadura não foi, necessariamente, muito nítida, muito clara, o retorno à democracia também não tenha sido.

\section{LEONILDE SERVOLO DE MEDEIROS:}

Também não, também não. A partir dos anos 1980, há um progressivo esforço de quantificação da violência e construção de indicadores.

\section{CRISTINA BUARQUE DE HOLLANDA:}

Uma coisa que você consegue reconstituir só com memória, né?

\section{LEONILDE SERVOLO DE MEDEIROS:}

As memórias te ajudam a ter uma dimensão qualitativa do que ocorreu, mas não há como reconstituir a violência no passado em números. A Comissão Pastoral da Terra, desde que foi criada, em 1975, começou a expandir sua ação para diferentes locais e a fazer registro dos conflitos, a quantificar e a criar dados. Num primeiro momento, de uma forma pouco rigorosa, eu diria. Depois eles foram sofisticando a metodologia e criando categorias de grupos sociais, categorias de violência e construíram, efetivamente, um banco de dados extremamente cuidadoso. Os dados da CPT, que começam a ser publicados, sistematicamente, a partir de 1985, permitem ver que os limites entre ditadura e democracia podem ser frágeis...

\section{CRISTINA BUARQUE DE HOLLANDA:}

Entendi.

\section{LEONILDE SERVOLO DE MEDEIROS:}

E a sistemática é a mesma: muitos casos mostram a ação do poder privado. Quando há instauração de processos, quando muito se chega ao executor, raramente ao mandante. Esse trabalho da CPT é extremamente rico para nos fazer pensar justamente sobre o quanto as fronteiras entre ditadura e democracia, em alguns planos, em especial no plano dos direitos humanos, são fluidos... Mas não se pode dizer que eles se apagam. Porque o simples fato de poder fazer esse levantamento, de publicar os dados, torná-los públicos, organizar debates em torno deles é, sem dúvida, uma conquista democrática.

\section{CRISTINA BUARQUE DE HOLLANDA:}

Claro, isso diz sobre os regimes.

\section{LEONILDE SERVOLO DE MEDEIROS:}

É! Mostra uma diferença importante.

\section{CRISTINA BUARQUE DE HOLLANDA:}

Esses representantes dos movimentos sociais que estavam presentes na Comissão eram figuras que tinham alguma história pessoal de afetação pela violência de Estado? 


\section{LEONILDE SERVOLO DE MEDEIROS:}

Não sei te responder com precisão. A pessoa que conheci melhor pessoalmente, porque já conhecia também de outros tempos, era uma advogada. E ela foi afetada pelas questões por ser uma advogada sindical, não era uma questão de afetação pessoal. Pelo menos nos casos que conheci não vi ninguém falar "ah, mataram meu pai", ou avô, irmão, tio...

\section{CRISTINA BUARQUE DE HOLLANDA:}

Imagino que vocês tenham lidado - você já chegou a mencionar - com essa presença do Araguaia, que tende a colonizar a abordagem da questão camponesa durante a ditadura. Por exemplo, alguns críticos à Comissão do Pará dizem: "eles só estão preocupados com o Araguaia quando, na verdade, já é um assunto que foi muito explorado e existem inúmeras outras situações que ficam apagadas como resultado dessa ênfase". Imagino que isso também tenha pesado sobre o trabalho de vocês. Vocês se preocuparam em modular a presença do Araguaia na agenda de trabalho vocês?

\section{LEONILDE SERVOLO DE MEDEIROS:}

É, é isso, foi um caso, importante, mas um caso dentre outros.

\section{CRISTINA BUARQUE DE HOLLANDA:}

Isso chegou a ser conversado, discutido por vocês?

\section{LEONILDE SERVOLO DE MEDEIROS:}

Muito, porque a nossa questão com o grupo Camponeses e Indígenas da CNV (e nós dialogávamos só com o caso dos camponeses, sabíamos que havia outras pessoas tratando da questão indígena, mas nenhum de nós tinha conhecimento acumulado sobre o tema) era que não dá para pensar a violência no campo só a partir da entrada dos grupos de esquerda. Eu acho que a Comissão da Verdade foi capturada pela ideia de visibilizar, tratar das organizações clandestinas de esquerda. Capturada no sentido de...

\section{CRISTINA BUARQUE DE HOLLANDA:}

A atenção dela.

\section{LEONILDE SERVOLO DE MEDEIROS:}

A atenção dela ficou muito nisso, muito.

\section{CRISTINA BUARQUE DE HOLLANDA:}

Quer dizer, o momento em que se interessa pelo campo é quando as organizações de esquerda vão para lá.

\section{LEONILDE SERVOLO DE MEDEIROS:}

Exatamente. Daí o peso que a guerrilha do Araguaia ganhou, até porque foi o investimento mais significativo, mais duradouro e enraizado de um grupo de esquerda no campo. A importância da guerrilha do Araguaia é inegável. Mas não dá para dizer que ela sintetiza as lutas no período tratado pela Comissão da Verdade. Eu diria que muito pelo contrário. Nosso esforço era tentar relativizar isso. Eu lembro que uma vez Maria Rita me ligou para saber de Cachoeiras de Macacu, onde houve um princípio de princípio de organização de um grupo de guerrilha pelo Colina (Comando de Libertação Nacional), que foi desbaratado rapidamente. Um dos camponeses foi morto e os outros foram retirados do estado e levados para o Maranhão. O padre que estava envolvido foi preso logo depois, ficou mais de 
dois anos na cadeia e foi muito torturado. Quando ela ligou, nós estávamos começando a pesquisar esse caso, mas o que nos interessava era fundamentalmente a dinâmica dos conflitos fundiários e da resistência no local, a ação do Instituto Brasileiro de Reforma Agráriaix. Nós tínhamos ouvido falar desse grupo, mas chegamos a ele depois. ${ }^{x}$ Em Duque de Caxias também houve uma situação parecida. A nossa questão era a presença de conflitos que eventualmente se encontravam com organizações de esquerda.

Eventualmente, não necessariamente. O conflito ultrapassava, de longe, a ação da esquerda armada, porque era um conflito estrutural e que, obviamente, naquele contexto, recebe um tratamento, eu diria com alguma segurança, mais repressivo justamente porque não havia canais de denúncia pública. Um dos casos significativos que apontamos no Relatório da CCV foi o do Aparecidão, em São Paulo. Uma liderança local que foi internada num hospital psiquiátrico. O professor José de Souza Martins, da USP, já tinha acompanhado uma pesquisa sobre o conflito que ocorreu no interior paulista e no qual Aparecido Galdino Jacinto foi uma das lideranças. Quando soube da internação, deslanchou uma grande mobilização, no final dos anos 70, início dos anos 80, para tentar libertar esse camponês. É um caso de outra ordem de violência. $O$ interesse da Comissão Camponesa era mostrar a dimensão dos conflitos no campo, das mortes, das violências, embora sem quantificar, pois não tínhamos condição, mas tentando chamar a atenção para o quanto era disseminada no país inteiro e a importância de olhar para isso. E nós buscávamos fazer listas de nomes, das formas de conflito, mas... A maior parte das nossas pesquisas era sobre conflitos, não sobre a presença da esquerda, nem exatamente sobre a repressão. Obviamente, em grande parte das pesquisas, pelo menos pesquisas feitas ao longo da década de 1980, que foi um momento de crescimento dos trabalhos sobre os conflitos no campo, se houvesse presença, no início, de alguém que se identificasse como de esquerda, ninguém mencionava, em razão do momento em que se vivia. Ninguém falava ou porque não conhecia, ou porque talvez não aparecesse como tão relevante, ou porque tinha medo.

\section{CRISTINA BUARQUE DE HOLLANDA:}

E você sentiu, em algum momento, animosidade em relação à questão camponesa dentro do mundo da justiça de transição? Sobre o Araguaia, por exemplo, há quem se ressinta de camponeses que teriam delatado guerrilheiros e que, a despeito disso, foram contemplados com indenização da Comissão de Anistia.

\section{LEONILDE SERVOLO DE MEDEIROS:}

Nunca senti animosidade nas discussões. Eu acho que havia uma certa indiferença, como se não fosse relevante. O Brasil tem uma relação complicada com sua face rural, uma relação difícil. Por mais que tenham se disseminado outras concepções, a ideia do atraso ainda pesa.

\section{CRISTINA BUARQUE DE HOLLANDA:}

Leonilde, veja se faz sentido: como não parte dos camponeses um discurso articulado contra o regime, então não se pode dizer que a repressão que recai sobre eles seja propriamente política. A luta deles tem objeto mais imediato, não é dirigida às estruturas.

\section{LEONILDE SERVOLO DE MEDEIROS:}

É, mais ou menos isso, porque, na verdade, eles estão lutando pelas coisas mais imediatas. Eu acho que o próprio sindicalismo rural, que é o grande personagem desconhecido nessa história, ao longo da ditadura conseguiu articular um discurso em torno da reforma agrária e dos direitos trabalhistas e impulsionou algumas dessas lutas... 


\section{CRISTINA BUARQUE DE HOLLANDA:}

Esse sindicalismo vinculado à...

\section{LEONILDE SERVOLO DE MEDEIROS:}

À Contag, Confederação Nacional dos Trabalhadores na Agricultura.

\section{CRISTINA BUARQUE DE HOLLANDA:}

A Contag. E o Partido Comunista nessa época já tinha sofrido muito com a ditadura...

\section{LEONILDE SERVOLO DE MEDEIROS:}

O Partido Comunista, depois do golpe, estava sendo destroçado. A repressão se abateu muito fortemente, principalmente sobre ele. Mas algumas pessoas próximas ao PCB estavam na Contag, como assessores jurídicos, educacionais. No caso do Rio de Janeiro, nos chamou muito a atenção a ação de alguns advogados que também atuavam em nível nacional na Contag. Todos eles foram do movimento estudantil, militantes de grupos de esquerda, ficaram presos, e depois de formados foram atuar junto aos trabalhadores rurais, como profissionais, mas carregavam consigo ideias e uma matriz de pensamento que ficou marcada nas suas práticas... Nas assessorias a mesma coisa. Dos militantes do campo que tiveram vínculo com a esquerda nos anos 1950/1960, acho que poucos retomaram o trabalho sindical e tiveram um lugar nos sindicatos. Eu conheci um, por exemplo, da Bahia, que foi um militante importante das oposições sindicais - inclusive eu o conheci em atividades do Departamento Nacional dos Trabalhadores Rurais da CUT [Central Única dos Trabalhadores], no final dos anos 80 . Não sei se fora um quadro expressivo, mas tinha tido proximidade com o PCdoB. Não dá para dizer que os militantes sumiram e que nada mais existiu. As lutas e ideias anteriores deixaram marcas que foram orientadoras de ações. Eles aprenderam nesse período tanto em termos do que poderiam chegar a obter, quanto em termos dos cuidados que deveriam ter. Há algumas coisas que escrevi sobre a Contag em que chamo sempre a atenção para a ideia de uma ação por dentro da lei, ao longo dos anos 1970, e que é produto de uma estratégia muito pensada, entende? O que dá para fazer e como dá para fazerxi. Em termos da Comissão Camponesa, procurávamos estar atentos justamente a essa dinâmica de luta independentemente de estar vinculada a grupos de esquerda ou não. O que importava era a existência de conflitos e o tratamento que receberam, em alguns lugares com uma repressão mais forte, em outros mais leve, outros ainda com negociação... Um caso que apontamos é o de um conflito em Magé, Rio de Janeiro, cujo resultado foi a desapropriação da fazenda em disputa, ainda em meados dos anos 70. Um dos raros casos de desapropriação no período ditatorial. Enfim, foram diferentes as ações. Um outro aspecto, que talvez complemente essa abordagem e mostre como as experiências com a questão dos trabalhadores se articulava, foi a experiência do GT [Grupo de Trabalho] 13 da CNV, voltado para a repressão dos trabalhadores urbanos... Fui a duas ou três reuniões deles em São Paulo. Foi um GT criado tardiamente e foi uma dificuldade para seus componentes, muitos deles de origem sindical, chamar a atenção para a repressão no interior das fábricas.

\section{CRISTINA BUARQUE DE HOLLANDA:}

Era sobretudo um GT tomado pela questão urbana, né?

\section{LEONILDE SERVOLO DE MEDEIROS:}

Operários urbanos. 


\section{CRISTINA BUARQUE DE HOLLANDA:}

Não teve questão rural?

\section{LEONILDE SERVOLO DE MEDEIROS:}

Não. Eu fui lá porque eu queria saber o que eles estavam discutindo justamente porque me incomodo muito com essa repartição. Fui a algumas reuniões e achei muito interessante... 0 José Sérgio Leite Lopes também ia.

\section{CRISTINA BUARQUE DE HOLLANDA:}

Eram reuniões abertas?

\section{LEONILDE SERVOLO DE MEDEIROS:}

Mais ou menos, abertas em termos. Havia convites. Eu fui porque eles acharam também interessante que alguém da Comissão Camponesa estivesse lá. Eu fui a duas ou três reuniões e me chamou muito a atenção o fato de haver uma dificuldade muito grande em tratar o caso do chão das fábricas. Quem liderava esse Grupo 13 era o pessoal herdeiro da antiga oposição sindical metalúrgica de São Paulo. E eles conseguiram, depois do fim da Comissão da Verdade, algumas coisas extremamente interessantes com relação à Volkswagen, por exemplo. Essa própria empresa acabou indicando historiador para pesquisar o caso e reconheceu a repressão ocorrida na fábrica. Os componentes desse GT, ou pelo menos alguns deles, continuam trabalhando, buscando aprofundar outras situações, não mais com um grupo com o nome de GT. Esse grupo em torno da antiga oposição metalúrgica de São Paulo continua tentando avançar.

\section{CRISTINA BUARQUE DE HOLLANDA:}

Sebastião Neto é uma figura, não é?

\section{LEONILDE SERVOLO DE MEDEIROS:}

É, o Neto acho que é o principal incentivador dessa discussão. Mas aí é fora, não é mais contexto da Comissão de Verdade. São vazios que a Comissão da Verdade deixou, mas que estimulam a pesquisa. Vazios importantes.

\section{CRISTINA BUARQUE DE HOLLANDA:}

E vocês [na Comissão Camponesa] chegaram a ter alguma interlocução com a Comissão de Anistia?

\section{LEONILDE SERVOLO DE MEDEIROS:}

Formalmente não. Apenas com algumas pessoas que eventualmente apareceram nas reuniões, mas nunca tivemos uma relação formal.

\section{CRISTINA BUARQUE DE HOLLANDA:}

E imagino que tampouco os arquivos deles tenham servido para vocês, porque a questão camponesa lá também deve estar pouco representada.

\section{LEONILDE SERVOLO DE MEDEIROS:}

Os casos que estão lá são casos mais conhecidos...

\section{CRISTINA BUARQUE DE HOLLANDA:}

O Araguaia. 


\section{LEONILDE SERVOLO DE MEDEIROS:}

Não só o Araguaia, há outros casos. Mas eram lideranças mais conhecidas. Por exemplo, um dos casos de uma das lideranças aqui ao Rio de Janeiro, que chegou a ser anistiado, é o do Bráulio Rodrigues da Silva, que mencionei anteriormente. Quando fiz a biografia dele, ele já estava anistiado, morava num assentamento rural em Magé, na casa inclusive que construiu com o valor recebido. Nosso desafio era entrar nesse mundo do não conhecido.

\section{CRISTINA BUARQUE DE HOLLANDA:}

Dos anônimos que foram atingidos.

\section{LEONILDE SERVOLO DE MEDEIROS:}

É, era essa a nossa dificuldade.

\section{CRISTINA BUARQUE DE HOLLANDA:}

Uma última questão, Leonilde: essa categoria "camponês", vocês a mobilizaram para dar nome à Comissão. Ela é uma categoria que faz sentido para esses trabalhadores nos diferentes lugares e regiões do país, ou ela enseja entendimentos locais diferentes?

\section{LEONILDE SERVOLO DE MEDEIROS:}

A categoria "camponês" tem historicamente um sentido político. Ela começa a ser usada no país dessa forma justamente nos anos 1950,60. Vem da herança da esquerda, da ideia de uma Aliança Operária Camponesa. Quem estava mobilizado acabava sendo identificado como camponês, suas lutas eram identificadas como lutas camponesas. Camponês tornouse uma identidade política. Olhando os documentos da Contag dos anos 70, o termo camponês aparece uma vez ou outra, pois nesse período se impõe um novo termo que é o trabalhador rural: genérico, neutro, aquele que vive do trabalho, não tem muita conotação política e tem base legal (o Estatuto do Trabalhador Rural), como aponta Moacir Palmeira...

\section{CRISTINA BUARQUE DE HOLLANDA:}

Entendi, mais asséptico assim.

\section{LEONILDE SERVOLO DE MEDEIROS:}

Exatamente, sem muita conotação política.

\section{CRISTINA BUARQUE DE HOLLANDA:}

E surge quando esse termo "trabalhador rural"?

\section{LEONILDE SERVOLO DE MEDEIROS:}

Ele começa a ser usado quando é instituída a categoria trabalhador rural legalmente, inicialmente com o próprio Estatuto do Trabalhador Rural, que é de 1963, que define o trabalho assalariado, mas que considera como trabalhador rural também o proprietário que tenha até um módulo rural e que produza com a sua famíliaxii.

\section{CRISTINA BUARQUE DE HOLLANDA:}

Quem se diz camponês tende a ser diferente de quem se diz trabalhador rural ou são identidades intercambiáveis? 


\section{LEONILDE SERVOLO DE MEDEIROS:}

Às vezes não, porque, na verdade, nenhum dos dois corresponde a uma identidade cotidiana, mas a determinadas relações.

\section{CRISTINA BUARQUE DE HOLLANDA:}

É um tipo de identidade reivindicada na esfera pública?

\section{LEONILDE SERVOLO DE MEDEIROS:}

É, são camponeses quando mobilizados politicamente, são trabalhadores rurais, porque eles se reconhecem como trabalhadores, porque são filiados ao sindicato dos trabalhadores rurais e portadores de determinados direitos, entende? Mas quando você pensa nas situações cotidianas, de vida e trabalho, eles são boias-frias, são assalariados, são posseiros, são foreiros, colonos, parceleiros...

\section{CRISTINA BUARQUE DE HOLLANDA:}

Aí tem um vocabulário imenso.

\section{LEONILDE SERVOLO DE MEDEIROS:}

Imenso! Imenso! Um vocabulário local imenso. Mas que se unifica do ponto de vista legal e do ponto de vista político também. Nos anos 70, a categoria de maior vigência é essa: trabalhador rural. Especialmente depois da criação da previdência social rural, com o Funrural. $O$ sindicato era a instituição que poderia atestar que determinada pessoa era trabalhador e que, portanto, tinha direito à previdência. Isso faz muita gente convergir para o sindicato, ele ganha alguma densidade de associados, o que não significa necessariamente uma densidade de lutas e de ações políticas. Nos anos 1980, essa identidade "trabalhador rural" também implode, mas ainda não se fala em camponês. Aparecem: sem terras, seringueiros, quebradeiras de coco, posseiros, assentados. 0 termo camponês vai ser recriado politicamente nos anos 90 .

\section{CRISTINA BUARQUE DE HOLLANDA:}

Então ele surge lá nos 50, 60 e cai de uso.

\section{LEONILDE SERVOLO DE MEDEIROS:}

Isso, pensando no uso político, enquanto identidade política. E é retomado no final dos anos 90 com a articulação da Via Campesina. O Brasil não teve participação na criação da Via, mas se articulou com ela muito cedo, por meio do MST, e hoje tem uma importância grande nela.

\section{CRISTINA BUARQUE DE HOLLANDA:}

E quando vocês criam a Comissão, o nome Comissão Camponesa chegou a ser discutido ou era uma categoria que já estava lá disponível e que fazia sentido usar?

\section{LEONILDE SERVOLO DE MEDEIROS:}

Fazia sentido... Em diferentes momentos alguns sindicalistas falavam em "camponês". Era trabalhador rural, mas num discurso mais solto falava em camponês, porque é uma categoria que marcou muito os anos 60. E que depois, enfim, acho que ela pode ser lida em vários planos. Nesse plano político, como disse antes, ela renasce no final dos anos 90, por meio da Via Campesina. O Movimento dos Trabalhadores Sem Terra fala "nós, camponeses"; o Movimento dos Pequenos Agricultores fala "nós, camponeses". 0 
revivescimento político da categoria camponesa foi marcante nesse momento. Em meados dos anos 1990 começou-se a falar em "agricultor familiar", termo utilizado em políticas públicas, em especial de crédito. Mas há um outro percurso da categoria que é analítico, teórico. Há uma tradição que vem tanto dos estudos influenciados pela sociologia francesa, como é o caso da professora Maria Isaura Pereira de Queiroz, da USP, que tem um texto de 60, "O Campesinato Brasileiro", quanto da antropologia. Os pesquisadores do Museu Nacional, já no final dos anos 60, retomam toda a literatura originária da Europa Oriental e da Ocidental. Shanin, Chayanov se tornam leitura obrigatória.

\section{CRISTINA BUARQUE DE HOLLANDA:}

Você comentou o envolvimento com o pessoal do Museu e eu lembrei que também na questão indígena eles tiveram uma entrada importante.

\section{LEONILDE SERVOLO DE MEDEIROS:}

Tiveram, com certeza, mas eram outros grupos de pesquisadores.

\section{CRISTINA BUARQUE DE HOLLANDA:}

É curioso como esses grupos sociais que ficaram à margem dos processos de Memória e da Verdade chegam neles com mediação da Universidade.

\section{LEONILDE SERVOLO DE MEDEIROS:}

É, os pesquisadores se tornaram, de alguma forma, difusores e impulsionadores dessas vozes. E fazem isso não por acaso. Não é a universidade, são grupos dentro da universidade que têm minimamente alguma articulação com esses grupos por conta de pesquisa.

\section{CRISTINA BUARQUE DE HOLLANDA:}

Isso.

\section{LEONILDE SERVOLO DE MEDEIROS:}

Estamos falando do campesinato e acadêmicos. Eu, por exemplo, participei de um outro grupo, que elaborou uma série de livros chamada "História Social do Campesinato". Foram nove volumes, editados pela Unesp (Universidade Estadual Paulista) abordando diferentes faces do campesinato. Foi demanda do Movimento dos Pequenos Agricultores (MPA), interessado em jogar luzes sobre o lugar do campesinato na história do Brasil. A academia é chamada para ajudar nessa visibilização.

\section{CRISTINA BUARQUE DE HOLLANDA:}

Mobilizar suas redes e cumprir uma certa função social.

\section{LEONILDE SERVOLO DE MEDEIROS:}

Isso. Dar visibilidade, a partir de um selo de legitimidade acadêmica...

\section{CRISTINA BUARQUE DE HOLLANDA:}

No caso indígena - e não sei se em alguma medida também no camponês - tem um desafio de fundo para esses acadêmicos que é o de promover uma mediação com o mundo formal, institucional. Os mediadores falam a língua do Estado e buscam se aproximar do universo de compreensão dos grupos nativos. Fazem um meio de campo. 


\section{LEONILDE SERVOLO DE MEDEIROS:}

É um processo de mediação mesmo. Se formos pensar este universo camponês, não com a mesma intensidade dos indígenas, porque aí tem barreira inclusive linguística, uma barreira mais radical, porque embora a linguagem dos camponeses também seja um tanto difícil de decifrar, falamos a mesma língua. No caso dos indígenas é mais complicado, mas a universidade tem tido um papel importante nessa mediação. O papel de tirar do anonimato. Se você for olhar a trajetória de algum desses acadêmicos, que são reconhecidos, vai ver que vários deles têm um pé nessa mediação camponesa de uma maneira, às vezes, bem intensa. Você pega uma figura como o Moacir Palmeira, por exemplo. Ele foi assessor da Contag, assessor profissional, licenciou-se do Museu e foi para Brasília para trabalhar como assessor educacional. O Afrânio Garcia a mesma coisa, assessorando a Federação sindical do estado do Rio de Janeiro. Isso indica um tipo de compromisso e, por outro lado, pesa na maneira como compreendem os processos das lutas no campo.

\section{CRISTINA BUARQUE DE HOLLANDA:}

É um tremendo desafio para o acadêmico: aproximar-se do objeto a ponto de falar em nome dele, mas não deixar de tê-lo como objeto.

\section{LEONILDE SERVOLO DE MEDEIROS:}

Mas há um outro lado, bastante interessante. Sem um mínimo de aproximação e adesão, você não chega a determinadas dimensões do "objeto".

\section{CRISTINA BUARQUE DE HOLLANDA:}

Claro, não se comunica com ele.

\section{LEONILDE SERVOLO DE MEDEIROS:}

Você chega até um determinado ponto.

\section{CRISTINA BUARQUE DE HOLLANDA:}

Chega na borda.

\section{LEONILDE SERVOLO DE MEDEIROS:}

É, chega na borda. Para chegar ao cerne não é muito fácil, porque há várias porteiras para atravessar. Eu mesma tive uma experiência muito rica com o grupo do extinto Centro Ecumênico de Documentação e Informação, que dava assessoria para o Departamento Nacional dos Trabalhadores Rurais da CUT. A gente percebia claramente até onde poderia ir. Há círculos, barreiras que você tem que ir atravessando, mas há espaços intransponíveis.

\section{CRISTINA BUARQUE DE HOLLANDA:}

E que, para conseguir superar, você só consegue se for reconhecido como alguém fiel ao grupo.

\section{LEONILDE SERVOLO DE MEDEIROS:}

Exatamente. Fiel no sentido mais forte da palavra, no sentido de ser capaz de colocar o grupo como prioridade. Então ligam e dizem: "olha, precisamos de não sei o quê para amanhã" e você tem que atender. O dizer "não" afasta... É isso: aproximações diferenciais. Mas, por outro lado, dá margem à compreensão de determinados processos aos quais, se você não está minimamente dentro, como pesquisador "de fora", não consegue atingir. E você toma as narrativas tal como são passadas, não há elementos para questionar. 


\section{CRISTINA BUARQUE DE HOLLANDA:}

Se não tem esse laço de proximidade, você só tem acesso à fala estruturada, que é para o mundo externo. Muito organizada, sem as tensões, né?

\section{LEONILDE SERVOLO DE MEDEIROS:}

Claro! Quando nos aproximamos, começamos a ver que as coisas não são tão lineares.

\section{CRISTINA BUARQUE DE HOLLANDA:}

Em algumas Comissões da Verdade, eu observei que sentidos de representação surgiam com muita naturalidade. Como muitos comissionados tinham sido eles próprios presos, perseguidos e exilados, eles tinham proximidade com o perfil das pessoas que davam testemunhos. Sem maiores reflexões a respeito, com muita naturalidade, eles usavam, por exemplo, a primeira pessoa do plural, sugerindo falar em nome de outros, dos perseguidos de uma certa cidade ou estado. Muitos articulavam isso com clareza. Imagino que na Comissão Camponesa não tenha havido ambiente para isso porque as diferenças entre os atores eram bem marcadas. Faz sentido isso?

\section{LEONILDE SERVOLO DE MEDEIROS:}

Faz, mas na Comissão Camponesa isso não havia. No caso da Comissão do Rio de Janeiro, por exemplo, não tinha nenhum. Se eu for pensar em representante, voz dos camponeses, não tinha nenhum. Aliás, acho que os camponeses tiveram um papel importante, tiveram um lugar na Comissão Estadual do Rio de Janeiro [CEV-Rio], por causa de um edital da FAPER] [Fundação de Amparo à Pesquisa do Estado do Rio de Janeiro] que ganhamos para pesquisar o tema.

\section{CRISTINA BUARQUE DE HOLLANDA:}

Ah, sim, você teve também essa relação com a CEV-Rio.

\section{LEONILDE SERVOLO DE MEDEIROS:}

No Rio de Janeiro, mais do que outros lugares, não se vê muito esse mundo camponês. A pesquisa acabou nos aproximando muito da Comissão da Verdade e dando um lugar para o campesinato que nunca imaginei... Porque, por exemplo, quando se pega o mundo do trabalho, operários, urbanos, você vê, eles apareceram muito menos no relatório, também no Rio de Janeiro.

\section{CRISTINA BUARQUE DE HOLLANDA:}

Talvez o campesinato tenha até tido mais destaque no relatório final da Comissão do Rio do que os trabalhadores urbanos, não?

\section{LEONILDE SERVOLO DE MEDEIROS:}

Não sei se mais destaque, mas acho que fomos mais longe em termos de pesquisa, de conseguir dados, porque estávamos trabalhando em um terreno relativamente difícil.

\section{CRISTINA BUARQUE DE HOLLANDA:}

Teve alguma articulação entre as comissões camponesa e a do Rio ou a temporalidade delas não coincidiu? Você aproveitou algum material de uma Comissão para outra? 


\section{LEONILDE SERVOLO DE MEDEIROS:}

Quando estávamos escrevendo o relatório da Comissão Camponesa, estávamos num estágio muito inicial da pesquisa aqui [no Rio]...

\section{CRISTINA BUARQUE DE HOLLANDA:}

Mas a comissão do Rio já dirigiu o edital para os temas de investigação ou os grupos que propuseram projeto que vieram com suas próprias agendas?

\section{LEONILDE SERVOLO DE MEDEIROS:}

Não, o edital era em torno dos Direitos Humanos, algo bem genérico.

\section{CRISTINA BUARQUE DE HOLLANDA:}

Então eles não induziram temas nesse grande universo?

\section{LEONILDE SERVOLO DE MEDEIROS:}

Não.

\section{CRISTINA BUARQUE DE HOLLANDA:}

Quer dizer que, se você não tivesse esse interesse de pesquisa no campo e não tivesse proposto a pesquisa, o tema dos camponeses não teria entrado?

\section{LEONILDE SERVOLO DE MEDEIROS:}

Talvez não, porque não ficamos sabendo quais projetos foram apresentados e quais os critérios de seleção.

\section{CRISTINA BUARQUE DE HOLLANDA:}

E não houve algum tipo de indução informal da candidatura?

\section{LEONILDE SERVOLO DE MEDEIROS:}

Não. Não houve isso. Conhecemos o pessoal da Comissão quando ganhamos o edital e começamos a ser chamados para reuniões. As agências de financiamento não tornam público o conjunto dos projetos que concorrem. Seria interessante ver o conjunto.

\section{CRISTINA BUARQUE DE HOLLANDA:}

Seria uma maneira de mapear...

\section{LEONILDE SERVOLO DE MEDEIROS:}

Mapear os temas que apareceram. Por exemplo, chama a atenção, aqui no Rio, que havia dois projetos vencedores sobre justiça, um sobre o BIP de Volta Redonda. Fiquei pensando em quais formam os critérios que marcaram a seleção dos projetos em relação ao conjunto do que foi apresentado e tenho a sensação que tem a ver com perfil acadêmico. Seria muito interessante ver os temas selecionados e o que ficou de fora, os critérios de seleção. No edital não era claro, não era muito explícito que tinha relação com a Comissão da Verdade. Era em torno de Direitos Humanos, de violação de direitos durante a ditadura. Eu mal conhecia o pessoal da Comissão da Verdade aqui no Rio de Janeiro, mas como eu estava envolvida na Comissão Camponesa e estava mergulhando aos poucos, retomando o tema da ditadura, que é um tema que sai e entra na minha vida, pensei: "é uma chance de poder fazer uma boa pesquisa sobre o Rio". Desde que eu vim morar neste estado, tive vontade de estudá-lo. Pesquisei assentamentos, sindicalismo... Tinha muito material acumulado. As 


\section{ENTREVISTA COM LEONILDE}

MEDEIROS

pesquisas sobre assentamentos me levaram a abordar conflitos por terra. Já tinha orientado dissertações e teses sobre o tema. Talvez essa seja umas das razões do projeto ter sido contemplado. Não estava partindo do zero. Já tinha investimento de pesquisa que facilitava, inclusive facilitava contatos. No CPDA [Programa de Pós-Graduação de Ciências Sociais em Desenvolvimento, Agricultura e Sociedade] há um núcleo de documentação, com um bom acervo sobre o tema.

\section{CRISTINA BUARQUE DE HOLLANDA:}

Leonilde, tem mais alguma coisa que você gostaria de acrescentar antes de fecharmos essa conversa?

\section{LEONILDE SERVOLO DE MEDEIROS:}

Talvez mais uma informação, porque a CCV criou alguns laços mais fortes entre algumas pessoas, que se desdobraram em outras pesquisas. Alguns pesquisadores concorreram a um edital sobre Memórias lançado ainda na época em que o Renato Janine [Ribeiro] era presidente da Capes [Coordenação de Aperfeiçoamento de Pessoal de Nível Superior]. Nós entramos com um projeto visando fazer biografias de algumas lideranças do Rio de Janeiro. Mas não fomos contemplados. O Sérgio Sauer ganhou um projeto desse mesmo edital para estudar Ligas Camponesas em Pernambuco e Master no Rio Grande do Sul, e articulou algumas pessoas da Comissão para desenvolver esse projeto. Estou envolvida nele. 0 importante é que houve continuidade do trabalho. Formalmente, a Comissão acabou, mas, na prática, algumas pessoas continuaram... De alguma maneira, há um núcleo duro que continua discutindo essas questões.

\section{CRISTINA BUARQUE DE HOLLANDA:}

Que bom saber disso. Muitíssimo obrigada. Aprendi muito com você hoje.

(Entrevista publicada em 2019)

\section{Cite esta entrevista}

MEDEIROS, Leonilde, 2019. Entrevista com Leonilde Servolo de Medeiros, conduzida por Cristina Buarque de Hollanda. Revista Estudos Políticos: a publicação semestral do Laboratório de Estudos Hum(e)anos (UFF).Rio de Janeiro, Vol.10 |N.2, pp. 135-159, dezembro de 2019.

\section{Notas}

1. Referência ao relatório final da CVV, que está disponível em:

https://cpdoc.fgv.br/sites/default/files/Relatório\%20Final \%20Comissão\%20Camponesa\%20da\%20Verdade\%20\%2009dez2014.pdf

2. Viana, Gilney. Camponeses mortos e desaparecidos: excluídos da Justiça de Transição. Brasília, DF: Secretaria 
de Direitos Humanos da Presidência da República, 2013

3. Em especial, Marco Antonio dos Santos Teixeira, que fez o mestrado sob minha orientação no CPDA e Fabrício Teló, que fez o doutorado também no CPDA.

4. Sauer, Sérgio et al. (orgs). Comissão Camponesa da Verdade: Relatório final: violações de direitos no campo 1946 a 1988. Brasília: Dex-UnB, 2015.

5. Autora, junto com Ana Carneiro, do livro Retrato da repressão política no campo - Brasil 1962-1985. Camponeses, mortos, torturados e desaparecidos. 2a. ed. Brasília: Ministério do Desenvolvimento Agrário, 2011. Esse livro foi um importante ponto departida para o trabalho da Comissão.

6. Referência ao Colóquio Arquivos, Verdade e Democracia, nos dias 20 e 21 de maio de 2019, ocorrido no Instituto de Estudos Sociais e Políticos da Universidade do Estado do Rio de Janeiro.

7. Ver: Silva, Braulio Rodrigues. Memórias da luta pela terra no Rio de Janeiro. Rio de Janeiro, Edur e Mauad X, 2008. Organização e notas de Leonilde Medeiros.

8. Carneiro e Cioccari, op. cit.

9. A respeito, ver Teló, Fabício e Medeiros, Leonilde. Violência e poder do Estado nos momentos iniciais do regime militar: a ação da Guarda Rural do Ibra, in Sales, Jean Rodrigues; Moraes, Luiz Edmundo de Souza; Bretas, Marcos Luiz e Sótenos, Abner Francisco. História escrita, história vivida. Rio de Janeiro: Lamparina e Faperj, 2019.

10. O tema se tornou objeto da tese de doutorado de Fabrício Teló, intitulada Organizações armadas e camponeses: comunicação, emoções e engajamento político (19681975), defendida no CPDA/UFRRJ em dezembro de 2019.

11. Medeiros, Leonilde. Trabalhadores do campo, luta pela terra e o regime civil-militar. In Pinheiro, Milton (org.) Ditadura: o que resta da transição. São Paulo: Boitempo, 2014.

12. Módulo rural é uma medida de área que tem por base a quantidade mínima de terra para sustentar uma família. Varia, conforme as regiões em função da qualidade da terra, regime de chuvas etc. 